\title{
Whom do customers blame for a service failure? Effects of thought speed on causal locus attribution
}

\author{
Natália Araújo Pacheco ${ }^{\mathrm{a}, \mathrm{b}, *}$, Maggie Geuens ${ }^{\mathrm{b}}$, Cristiane Pizzutti ${ }^{\mathrm{a}}$ \\ a School of Management, Federal University of Rio Grande do Sul, 855 Washington Luiz Street, Porto Alegre, Brazil \\ b Faculty of Economics and Business Administration, Ghent University, Tweekerkenstraat 2, 9000 Ghent, Belgium
}

\section{A R T I C L E I N F O}

\section{Keywords:}

Thought speed

Service failure

Causal attributions

\begin{abstract}
A B S T R A C T
This research investigates the impact of customers' thought speeds in a service failure setting. Fast-thinking induces not only heuristic processing, but also positive affect. As both factors predict a different outcome on whom customers blame for the failure, this study examines rival hypotheses. Findings from three experiments show that fast-thinking leads respondents to attribute failures to the service providers (i.e., showing a selfserving bias). In addition, fast-thinking also has more downstream consequences, as it negatively affects repurchase intentions and positively affects intentions to spread negative word of mouth. Therefore, service providers are encouraged to stimulate slow thought during service encounters.
\end{abstract}

\section{Introduction}

Thought speed refers to how fast or slow someone thinks. Individuals' thought speeds may be altered by situational factors, such as fast- or slow-moving images in the environment or how fast or slow a conversation develops. Thought speed has been shown to influence a variety of behavioural reactions. Fast thought speed (FTS), for example, leads to more risk taking (Chandler and Pronin, 2012), a higher selfconfidence and self-esteem, more creativity and a higher capacity for solving novel problems (Pronin, 2013).

Central to this study's investigation is that thought speed is also related to (1) cognitive processing and (2) affective reactions. Fast cognitive processing involves fast thinking (Pronin, 2013). According to the dual-process framework, individuals use two cognitive processes to think: the more intuitive, heuristic and faster System 1 and the more reflective, analytical and slower System 2 (De Neys, 2006; Kahneman and Frederick, 2002). System 2 monitors System 1, helping the latter when things get difficult (Kahneman, 2011). Although System 1 may be useful in situations requiring fast reactions, its reliance on simplifying heuristics may lead to errors and biases when System 2 fails to correct these (Kahneman and Frederick, 2002; Tversky and Kahneman, 1974).

Based on the thought speed and dual-process framework literature, stimulating FTS among customers may prompt the adoption of simplifying heuristics, such as "the customer is always right", as well as inhibit System 2 from correcting it. This process should lead to a selfserving bias after a service failure, that is, a tendency to attribute the failure to external causes, such as the service provider (Mezulis et al.,
1985).

However, FTS also induces more positive affect (Pronin et al., 2008; Pronin and Wegner, 2006), and the literature addressing mood as a resource (e.g., Raghunathan and Trope, 2002; Trope et al., 2001) would predict the exact opposite effect. Indeed, according to the mood as a resource literature, positive mood is a resource that helps people to process negative self-relevant information. When individuals lack positive mood, they may avoid such information. This avoidance may lead to a greater self-serving bias. Based on the findings of Pronin et al. (2008) and Pronin and Wegner (2006), individuals with FTS have more positive mood and, consequently, could be less likely to report selfserving bias. These rival predictions (i.e., that FTS could lead to either more or less self-serving bias) are examined and include an investigation into more downstream consequences such as the impact of thought speed on repurchase intentions and the intentions to spread negative word of mouth (NWOM).

To date, no study has been found that investigated the effect of thought speed on causal locus attribution and behavioural responses after a service failure. Understanding whether and how thought speed affects whom customers blame for service failures is important because service providers could use this knowledge to reduce customer selfserving bias. This reduction is beneficial for service providers because it means that customers will share some responsibility for the failures, which should decrease customers' negative affective and behavioural reactions towards the service providers (Hui and Toffoli, 2002). In other words, the reduction of self-serving bias among customers will diminish typical negative reactions, such as anger, avoidance, NWOM

\footnotetext{
* Corresponding author at: IMED Business School, Faculdade Meridional, 304 Senador Pinheiro Street, Passo Fundo, Brazil.

E-mail addresses: natalia.a.pacheco@gmail.com (N.A. Pacheco), maggie.geuens@ugent.be (M. Geuens), cristiane.pizzutti@ufrgs.br (C. Pizzutti).
} 
and intentions to complain and punish the service providers (Folkes, 1984; Weiner, 2000, 2014). In this paper, three experimental studies investigating the effect of thought speed on causal locus attribution, NWOM and repurchase intentions are presented.

\section{Thought speed, cognitive processing and affective responses}

Previous research shows that individuals' thinking speeds can have pervasive effects on their behavioural, cognitive and affective responses. Some scholars (e.g., Chandler and Pronin, 2012; Yang et al., 2014) argue that FTS leads to different outcomes when compared with both normal (NTS) and slow thought speeds (STS).

For instance, according to Pronin (2013), the occurrence of fast thoughts may serve as a signal to a person's mind and body that he or she may need to prepare for urgent action. The author suggests that the state of preparation for urgent action is responsible for increased energy, self-confidence, self-esteem, willingness to take risks, creativity and capacity for solving novel problems.

As previously stated, the relationships between thought speed and (1) cognitive processing and (2) affective responses are pertinent to this study. Concerning the former, although fast cognitive processing is often associated with easier cognitive processing (i.e., stimuli that are easy to process are quickly processed), the effects of thought speed cannot be explained by ease of cognitive processing (i.e., fluency) because FTS induces positive affect even when the stimuli are more difficult to process (Pronin, 2013). Whereas ease of processing cannot explain the effects of thought speed, different cognitive processes adopted by faster-thinking individuals could have implications for consumer behaviour. To understand cognitive processes that influence human judgement and choice, many authors (e.g., De Neys, 2006; Dhar and Gorlin, 2013; Saini and Thota, 2010) have adopted the dual-process or dual-system framework (Kahneman and Frederick, 2002). As mentioned, the proponents of this dual-process framework argue that our minds use two different cognitive processes, called System 1 and System 2, to make sense of things.

System 1 generates fast and intuitive answers to judgment problems using simplifying heuristics, which may sometimes lead to biases and systematic errors (De Neys, 2006; Kahneman, 2011; Tversky and Kahneman, 1974). For instance, when evaluating whether a tidy person with a need for order is more likely to be a librarian or a farmer, an individual applying System 1 may use resemblance as a simplifying heuristic to determine that a person who resembles the stereotype of a librarian is more likely to be a librarian. However, the fact that there are more farmers than librarians implies that this person is more likely to be a farmer (Kahneman, 2011). Although System 1 may lead to incorrect answers due to its reliance on simplifying heuristics, it results in correct answers in many other situations and is the system used in several activities, such as understanding simple sentences, solving simple math equations, driving a car on an empty road and detecting hostility in a voice (Kahneman, 2011). Generally, simplifying heuristics are useful and effective despite the possibility of errors and biases (Tversky and Kahneman, 1974).

In turn, System 2 is used in more complex activities requiring attention and effort, such as solving complicated math equations and filling out tax forms. Thus, thought speed is slower when applying System 2 (Kahneman, 2011). System 2 monitors the answers formulated by System 1 and endorses or corrects them. If this process is not successful, the errors and biases derived from the simplifying heuristics of System 1 are more likely to occur (Kahneman and Frederick, 2002). Analytical responses are expected to require more processing time than heuristic responses require (De Neys, 2006). Therefore, individuals with STS likely rely more on the slower analytical system, whereas individuals with FTS likely depend more on the faster heuristic system.

Thought speed and the dual-process framework could influence customers' reactions in several ways, including their responses to service failures. Specifically, whether customers think faster and rely more on System 1 or think slower and depend more on System 2 could influence other cognitions, such as causal attributions for a service failure. Because fast-thinking individuals more frequently adopt simplifying heuristics that may lead to biases (Tversky and Kahneman, 1974), they may be more likely to engage in cognitive biases, such as the self-serving bias, and make more external attributions for service failures than individuals with STS make.

According to Kahneman (2011), a person can walk and perform simple tasks at the same time, but when he or she is required to engage in effortful thinking to solve a problem, other tasks tend to be ceased so the cognitive resources can be directed to System 2 without hindrance. Based on this rationale, inducing individuals to think faster than usual could inhibit their use of System 2, creating a scenario where the heuristics and biases common to System 1 are no longer monitored and corrected. This idea reinforces the notion that individuals with FTS could engage more in self-serving bias than individuals with STS. Therefore, the following hypothesis is formulated:

H1a. Compared with STS, FTS will lead to more external causal attributions for a service failure.

Concerning affective responses, FTS (versus STS) seems to induce more positive affect (Pronin and Wegner, 2006; Pronin et al., 2008), an outcome that appears to be independent of thought content (elating versus depressing content) and ease of cognitive processing or fluency. FTS, thus, induces positive affect even when the thought content is more depressing and difficult to process (Pronin, 2013). In line with this findings, Yang et al. (2014) provide empirical evidence that the positive affect of individuals with mild to moderate depressive symptoms may be increased by inducing fast thoughts, as is the case for individuals with no depressive symptoms. In addition, studies suggest that FTS has no influence on negative affect (Pronin et al., 2008; Pronin and Wegner, 2006). As a consequence, FTS can be assumed to exert a net positive impact on individual affect or mood.

According to the mood as a resource literature (Raghunathan and Trope, 2002; Trope et al., 2001), positive mood serves as a resource that facilitates the processing of negative self-relevant information and makes it bearable. For instance, Raghunathan and Trope (2002) conducted an study in which individuals with high caffeine consumption read an article describing negative items about caffeine (representing negative self-relevant information). Those in a negative mood recalled fewer items from the article than those in a positive mood, which exemplifies that when individuals lack positive mood, they tend to avoid negative self-relevant information (Raghunathan and Trope, 2002). Because FTS is associated with a more positive mood (Pronin et al., 2008; Pronin and Wegner, 2006), FTS is likely also associated with the processing of negative self-relevant information and, consequently, a lower self-serving bias after a service failure. Thus, drawing from the mood as a resource literature, FTS (versus STS), in contrast to H1a, may induce less external attribution for a service failure. As such, the following rival hypothesis is formulated:

H1b. Compared with STS, FTS will lead to less external causal attributions for a service failure.

Besides an impact on causal attributions, FTS likely also has an effect on more downstream variables, such as spreading NWOM and repurchase intentions. This effect is expected to be explained (i.e., mediated) by the causal locus attribution. The literature shows that external locus attribution for a failure leads to more NWOM (Folkes, 1984; Richins, 1983) and avoidance or intention to switch (Richins, 1987; Weiner, 2000). Therefore, thought speed likely will influence external attribution ( $\mathrm{H} 1 \mathrm{a}$ and $\mathrm{H} 1 \mathrm{~b})$, which, in turn, will lead to more NWOM and less repurchase intention.

H2a. Thought speed will have an indirect effect on NWOM intention through the causal locus attribution. 
H2b. Thought speed will have an indirect effect on repurchase intention through the causal locus attribution.

Three studies were conducted to test the hypotheses. Study 1 tests the rival hypotheses $\mathrm{H} 1 \mathrm{a}$ and $\mathrm{H} 1 \mathrm{~b}$, and Studies 2 and 3 test all the hypotheses in different service failure situations.

\section{Study 1}

Study 1 involved a single-factor, between-subjects experiment, with 108 panel members from a large west European university $(59 \%$ women; $M_{\text {age }}=23.19 ; S D=5.80$ ).

\subsection{Procedure}

Thought speed was manipulated at two levels, FTS and STS, using a similar manipulation as Chandler and Pronin (2012) and Pronin and Wegner (2006). More specifically, the participants were exposed to trivia sentences (e.g., "All polar bears are left handed") at either a fast (40 ms per letter, 320-millisecond intervals between sentences) or a slow speed (170 ms per letter, 4,000-ms intervals between sentences). This manipulation took $2 \mathrm{~min}$ and $30 \mathrm{~s}$, which was similar to the duration adopted by Chandler and Pronin (2012) and Pronin and Wegner (2006). A pre-test with 84 participants from the same population of this study indicated that the manipulation was effective. In this pre-test, the participants assigned to the FTS condition reported thinking significantly faster than those under the STS condition $(F(1$, $82)=12.20 ; p<.001 ; M_{\text {fast }}=6.40 ; S D_{\text {fast }}=1.78 ; M_{\text {slow }}=4.80$; $S D_{\text {slow }}=2.37$ ).

After answering a manipulation check ("What did you feel was the speed of your thoughts as you were reading the statements on the computer screen?" [1 = very slow to $9=$ very fast]; Pronin and Wagner, 2006, p. 809), the participants read the following service failure scenario:

Imagine that you get to a hotel you have booked online a few weeks ago. At the reception desk, you mention your name, but the receptionist cannot find any booking for you. The receptionist asks if you remember seeing a confirmation message on the website where you made your booking. You do not remember this. The receptionist asks if you received a confirmation e-mail from the hotel, but you cannot answer that question because these kinds of e-mails usually go to your spam folder, and you have deleted all e-mails from that folder a couple of days ago. There is no room available at the hotel, so you will have to find another place to sleep. This is very inconvenient for you because you are in a hurry and have many things to do. Only after $15 \mathrm{~min}$ and several calls are you able to find a place to stay that night.

Next, the following question probed whether the respondents had read and understood the service failure scenario: "The story you read on the previous page was about: (a) you having a problem with a hotel reservation, (b) you having a problem to pay a hotel bill [or] (c) you being unable to speak to the hotel receptionist." Three participants who provided wrong answers (i.e., options b and c) were excluded from the final sample.

Causal locus attribution was measured as follows: "Is the cause of the problem at the hotel due to something about you or to something about other people or circumstances?" ( 1 = totally due to other people or circumstances to $7=$ totally due to me; adapted from Peterson et al. (1982)).

\subsection{Results}

A one-way ANOVA showed a significant effect of thought speed on locus attribution $(F(1,106)=4.42 ; p<.05)$. The participants assigned to the FTS condition reported more external attribution than those under the STS condition $\left(M_{\text {fast }}=3.82 ; S D_{\text {fast }}=1.34 ; M_{\text {slow }}=4.38\right.$; $S D_{\text {slow }}=1.43$ ), supporting H1a. To make sure the effect was genuine and not a statistical artefact, a second study was conducted to replicate this effect using a different manipulation, a different service failure scenario, and respondents from a different nationality. In addition, this second study tests H2a and H2b.

\section{Study 2}

Study 2 involved a single-factor, between-subjects experiment manipulating thought speed at two levels: FTS and STS. A total of 95 U.S., Mechanical Turk workers ( $51 \%$ men; $M_{\text {age }}=36.73$; $S D=11.89$ ) participated in this study.

\subsection{Procedure}

Customers can enter a service situation with a thought speed affected by previous circumstances, or their thought speed can change due to elements during the service encounter. In Study 1, by manipulating thought speed with trivia sentences first and presenting a service failure afterwards, the former situation was mimicked. In an effort to more closely mimic the latter situation, Study 2 had respondents reading sentences about a service failure in the required thought speed.

The sentences were presented at the same speed adopted in Study 1. Different from Study 1, where the same manipulation duration for the experimental conditions were maintained by having differences in the content of the manipulation (i.e., the FTS condition had more content than the STS condition), this time, the same content was retained and the manipulation duration was varied ( 40 and $150 \mathrm{~s}$ for the FTS and STS conditions, respectively). Study 2 was conducted in this way because providing more or less information about the service failure across the experimental groups would likely influence the participants' perceptions and attributions regarding the failure. Thus, all participants read the following text:

Imagine that you visit a car dealer. You see a new model that you like a lot. The show room car has a red interior with black seats. The salesperson calculates how much the car would cost with all your preferences (such as the red interior). You are pleased, but you decide to visit a few other dealers before the purchase. As you didn't find any better option, you return to this dealer the next day. The salesperson who helped you before has a day off, but his colleague helps you out. He mentions that all details of your request are still in the computer. He prints the offer and asks you to sign. When the car is delivered, it turns out that the interior is grey instead of red. You are very disappointed since you explicitly asked for the red interior at the first salesperson. The second salesperson did not ask you and just ordered the standard interior. And you did not notice it on the document you signed.

The participants answered the same manipulation check used in the pre-test from Study 1. Causal locus attribution was measured, as in Study 1 , but repurchase intention was also measured ("When I need a car dealer again in the future, I will choose this car dealer") and NWOM ("I am likely to speak negatively about this car dealer to others") using 7-point scales (items adapted from Choi and Mattila (2008)).

\subsection{Results}

The thought speed manipulation was effective $(F(1,93)=37.74$; $p<.001)$. The participants assigned to the FTS condition reported thinking faster than the STS group reported $\left(M_{\text {fast }}=6.40 ; S D_{\text {fast }}=\right.$ $1.75 ; M_{\text {slow }}=3.75 ; S D_{\text {fast }}=2.49$ ). Thought speed had a significant effect on locus attribution $(F(1,93)=3.96 ; p<.05)$. Replicating the result of Study 1, support for H1a was, again, noted in the sense that the FTS group reported more external attribution than the STS group ( $M_{\text {fast }}$ $=3.04 ; S D_{\text {fast }}=1.69 ; M_{\text {slow }}=3.75 ; S D_{\text {slow }}=1.77$ ). 
In addition, mediation analyses using Process model 4 (Hayes, 2013) were conducted to test H2a and H2b. Thought speed was dummy coded (STS $=-1$; FTS $=1$ ). The first analysis conducted with NWOM as the dependent variable showed significant paths between thought speed and locus attribution $(a=-.35)$ and between locus attribution and NWOM $(b=-.45)$. A bias-corrected bootstrap confidence interval for the indirect effect ( $a \times b=.16$ ) based on 5000 bootstrap samples showed that locus attribution was a significant mediator, as the interval did not include zero (from .003 to .346). That is, thought speed had an indirect effect on NWOM through locus attribution. There was no evidence that thought speed influenced NWOM independently of its effect on locus attribution $\left(c^{\prime}=-.15 ; p=.309\right)$.

The second mediation analysis conducted with repurchase intention as the dependent variable showed a similar effect of thought speed on locus attribution ( $a=-.35$ ) and the effect of locus attribution on repurchase intention $(b=.37)$. Locus attribution was a significant mediator because the confidence interval did not include zero (from .285 to -.003$)$. There was no evidence that thought speed influenced repurchase apart from its effect on locus attribution $\left(\mathrm{c}^{\prime}=-.22 ; p=\right.$ .123).

\subsection{Discussion}

This study's results support H1a, converging with the result of Study 1. Moreover, the findings show an indirect effect of thought speed on NWOM and repurchase intentions, supporting H2a and H2b. Faster thinking leads to higher external attribution, which, in turn, leads to higher intention to engage in NWOM and lower intention to repurchase.

Previous research suggests that FTS deviates from NTS, whereas STS does not. In other words, FTS is considered to be responsible for the previously reported affective, cognitive and behavioural responses. To see whether this finding is also the case in a service encounter, a third study was conducted that considers a NTS condition. Moreover, we try to provide stronger evidence for the effect of thought speed on causal locus attribution and its downstream consequences by again using a different service failure scenario.

\section{Study 3}

Study 3 involved a single-factor, between-subjects experiment. The thought speed was manipulated at three levels: FTS, NTS and STS. The NTS condition was introduced to check whether the STS or FTS condition (or both) would differ from the average thought speed effect. A total of 105 panel members from a large west European university $(52 \%$ women; $M_{\mathrm{age}}=20.58 ; S D=1.43$ ) participated in this study.

\subsection{Procedure}

Similar to Study 2, Study 3 manipulated thought speed by providing sentences about a service failure. These sentences composed a short version of the service failure described by Choi and Mattila (2008). The sentences were presented at the same speed adopted in Studies 1 and 2 for the FTS and STS conditions. The speed used for the NTS condition was $80 \mathrm{~ms}$ per letter, which was the average reading speed for Pronin and Wegner's (2006) sample. As in Study 2, the same content was retained and the manipulation duration varied (25, 47 and $90 \mathrm{~s}$ for the FTS, NTS and STS conditions, respectively). Participants read the following text:

Imagine that you are suffering from serious coughing. You decide to go to a hospital. A doctor examines you and prescribes something for your cough. You go to the check-out desk, but there is no service person at the desk. You have waited for about $30 \mathrm{~min}$, but no service person has shown up yet. There is another check-out desk around the corner, and other patients are making their payments there. You wonder whether there is any sign to inform patients of this other

\section{check-out desk.}

To check whether the fast pace of the sentences could compromise the participants' understanding of the service failure, a question about the content of the failure was asked. The fact that both STS and FTS conditions had nearly the same number of incorrect answers regarding the content of the service failure (13 and 14, respectively) suggested that the fast pace of the latter condition did not impair the participants' understanding. Thirty-two participants who gave an incorrect answer about the content of the failure were excluded. Afterwards, the participants had to answer the same manipulation check and causal locus attribution item from the previous studies. The same measure of repurchase and NWOM intentions from Study 2 were adopted. The amount of time the participants spent on each questionnaire page was also measured to check whether those assigned to the FTS condition were answering faster than their peers under the NTS and STS conditions.

\subsection{Results}

The thought speed manipulation was effective $(F(2,102)=25.11$; $p<.001)$. The results of the LSD post-hoc tests showed that the participants assigned to the FTS condition reported faster thinking than the NTS group $\left(M_{\text {fast }}=6.06 ; S D_{\text {fast }}=1.18 ; M_{\text {normal }}=4.68 ; S D_{\text {normal }}=\right.$ $1.52 ; p<.001)$, who, in turn, reported faster thinking than the STS group $\left(M_{\text {slow }}=3.30 ; S D_{\text {fast }}=1.88 ; p<.001\right)$. Moreover, additional proof supports the success of the manipulation by comparing the response times in the different conditions. That is, the participants differed in the time they spent on the pages measuring causal locus attribution $(F(2,102)=10.48 ; p<.001)$ and behavioural intentions $(F$ $(2,102)=9.85 ; p<.001)$. The participants assigned to the STS condition spent more time on the attribution $\left(M_{a t t}=14 \mathrm{~s} ; S D_{a t t}=6 \mathrm{~s}\right)$ and intentions pages $\left(M_{\text {int }}=25 \mathrm{~s} ; S D_{\text {int }}=8 \mathrm{~s}\right)$ than those under the NTS condition $\left(M_{\text {att }}=11 \mathrm{~s} ; S D_{\text {att }}=4 \mathrm{~s} ; p<.01 ; M_{\text {int }}=20 \mathrm{~s} ; S D_{\text {int }}=7 \mathrm{~s}\right.$; $p<.05$ ), who, in turn, spent more time on the pages than the FTS group $\left(M_{\text {att }}=9 \mathrm{~s} ; S D_{\text {att }}=2 \mathrm{~s} ; p=.05 ; M_{\text {int }}=18 \mathrm{~s} ; S D_{\text {int }}=5 \mathrm{~s} ; p=.27\right)$.

Importantly, thought speed had a significant effect on locus attribution $(F(2,102)=5.46 ; p<.01)$; the FTS group reported more external attribution than the STS group $\left(M_{\text {fast }}=2.77 ; S D_{\text {fast }}=1.50 ; M_{\text {slow }}\right.$ $\left.=4.00 ; S D_{\text {slow }}=1.68 ; p<.01\right)$. This result supports $\mathrm{H} 1 \mathrm{a}$, replicating the findings from Studies 1 and 2. The participants under the NTS condition also reported more external attribution than their counterparts assigned to the STS condition $\left(M_{\text {normal }}=3.17 ; S D_{\text {normal }}=1.41\right.$; $p<.05$ ), but in contrast to what we would expect on the basis of previous research, no significant difference in locus attribution was found between the FTS and NTS groups $(p=.28)$.

Mediation analyses were conducted to test H2a and H2b. Thought speed was dummy coded (STS $=-1$; NTS $=0$; FTS $=1$ ). The first analysis showed significant paths between thought speed and locus attribution $(a=-.62)$ and between locus attribution and NWOM $(b=$ - .27). A bias-corrected bootstrap confidence interval for the indirect effect ( $a \times b=.16$ ) based on 5000 bootstrap samples found locus attribution to be a significant mediator because the interval does not include zero (from .027 to .361). There was no evidence that thought speed influenced NWOM independently of its effect on locus attribution $\left(\mathrm{c}^{\prime}=-.09 ; p=.655\right)$. These results support H2a.

The second mediation analysis showed no indirect effect of thought speed on repurchase intention because the confidence interval includes zero (from - .260 to .001). This result does not support H2b. Although there was no evidence for the indirect effect of thought speed on repurchase intention, regression analysis showed a significant effect of locus attribution on repurchase ( $t=2.06 ; \beta=.20 ; p<.05$ ), indicating that the less external the attribution, the higher the intention to repurchase. 


\subsection{Discussion}

The results of Study 3 replicate and extend the findings from Studies 1 and 2 regarding the effect of thought speed on causal locus attribution. The fact that there is no difference in locus attribution between the FTS and NTS groups (i.e., only the attributions from the STS group differed from those of the NTS group) suggests that STS could lead to less external attribution, rather than FTS leading to more external attribution. The reason for this result probably is that the individuals assigned to the STS condition use System 2 and can, therefore, override a self-serving bias. The longer time it takes to answer the causal attribution and behavioural intentions questions serves as evidence of an analytical system (System 2) in use, whereas a shorter time (i.e., a fast answer) indicates the adoption of a heuristic system (System 1; De Neys, 2006). These findings suggest that the implications for consumers thinking in a normal thought speed are similar to thinking in a fast speed, with both leading to a higher self-serving bias after a service failure. Therefore, slowing down customers' thought speeds seems desirable for service providers.

Moreover, the effect of thought speed on NWOM through locus attribution was replicated. The lack of a significant indirect effect on repurchase intention may be due to the small sample size (i.e., 105 cases for 3 experimental conditions). However, the regression analysis suggests that the effect of thought speed on locus attribution is still managerially relevant, since the latter variable affects repurchase intention.

\section{General discussion}

The results from the three studies show that FTS (versus STS) leads to more external attribution for a service failure. The dual-process framework offers a reasonable explanation for the mechanism behind the effect of thought speed on causal locus attribution. Individuals with STS take more time to deliberate on who is to blame for a service failure, using a more analytical system (System 2), which is able to override heuristic thoughts, such as "the customer is always right", and self-serving bias. However, individuals with FTS take less time to deliberate, predominantly using System 1, which is guided by heuristics and, thus, more susceptible to bias (De Neys, 2006; Kahneman and Frederick, 2002).

From a theoretical perspective, this research contributes to the extant literature in at least four ways. First, this study contributes to consumer behaviour literature by showing that thought speed is linked to attributional thoughts and, consequently, behavioural intentions. There is reason to believe that this link is explained by the dual-system framework and not by the mood as a resource rationale. To date, this is the first study to explore the effect of thought speed on causal locus attribution and more downstream consequences. Second, this study contributes to decision-making literature by evidencing that intuitive decision making, triggered by fast thoughts, is linked to the likelihood of engaging in a self-serving bias. Third, this study contributes to the literature on thought speed by showing that not necessarily FTS is responsible for the differences between FTS and STS respondents. In the service failure situations investigated here, the STS condition was more likely to deviate from the NTS condition. Finally, this study contributes to the service literature by showing that a failure situation could lead to different causal attributions and behaviours depending on the consumer's thought speed.

From a managerial perspective, this research contributes by showing that service providers may slow down consumers thought speed to reduce the blame that these consumers attribute to service providers after a service failure. Because thought speed is influenced by external stimuli, such as the manipulations used in our experiments and the ones of Pronin and Wegner (2006) and Pronin et al. (2008), service providers may use environmental stimuli (e.g., slow motion videos and slow tempo music) to slow down consumers thoughts. Besides reducing the self-serving bias after a service failure, slowing down customers' thoughts through slow-tempo music could lead to relaxation, approach behaviours, increased pleasure and satisfaction with some service encounters (i.e., those services in which customers seek low arousal; Bruner, 1990; Mattila and Wirtz, 2001; Milliman, 1986).

Moreover, frontline employees could be trained to talk in a calm and relaxed way, which could further stimulate STS among consumers. Both the environmental (i.e., videos and music) and social (interaction between employee and consumer) stimuli could be adopted in service encounters, as well as in service recovery situations. These results show that reducing the self-serving bias after service failures by slowing down consumers' thoughts is desirable because it leads to higher repurchase and lower NWOM intentions.

\subsection{Limitations and suggestions for future research}

Results of the three studies focus on the main effect of thought speed on causal locus attribution, but only Study 3 shows preliminary evidence that the dual-process framework is the mechanism behind this main effect (by investigating response times). Future studies could further examine this dual-process explanation by conducting more rigorous tests. For instance, besides using the time that participants take to answer a question as an indicator of whether System 1 or 2 is being used, which is the measure adopted by this study and De Neys (2006) for an identical purpose, future research could assess the extent to which participants use heuristic thoughts to answer questions, indicating the predominance of System 1. Kahneman (2011) reports many tests in which people give an intuitive incorrect answer to a problem, showing that the reliance on heuristics (typical of System 1) leads to biases. Similar tests could reinforce which system is in use.

Although the dual process seems a reasonable explanation for the main effect found in this study, future research could pursue alternative explanations. For instance, FTS leads to more positive affect and, in some cases, higher self-esteem (Pronin et al., 2008; Pronin and Wegner, 2006). People with positive affect and high self-esteem tend to respond more defensively to threats to their self-image than those with negative affect and low self-esteem, reporting a higher self-serving bias (Campbell and Sedikides, 1999). This defensive behaviour could be an alternative explanation for finding more external attribution for a service failure among individuals with FTS.

\section{Acknowledgements}

This research was supported by the Coordenação de Aperfeiçoamento de Pessoal de Nível Superior (CAPES) (Process no. 12858-13-7).

\section{References}

Bruner, G.C., 1990. Music, mood, and marketing. J. Mark. 54 (4), 94-104. http://dx.doi. org/10.2307/1251762.

Campbell, W.K., Sedikides, C., 1999. Self-threat magnifies the self-serving bias: a metaanalytic integration. Rev. Gen. Psychol. 3 (1), 23-43. http://dx.doi.org/10.1037/ 1089-2680.3.1.23.

Chandler, J.J., Pronin, E., 2012. Fast thought speed induces risk taking. Psychol. Sci. 23 (4), 370-374. http://dx.doi.org/10.1177/0956797611431464.

Choi, S., Mattila, A.S., 2008. Perceived controllability and service expectations: influences on customer reactions following service failure. J. Bus. Res. 61 (1), 24-30. http://dx. doi.org/10.1016/j.jbusres.2006.05.006.

De Neys, W., 2006. Automatic-heuristic and executive-analytic processing during reasoning: chronometric and dual-task considerations. Q. J. Exp. Psychol. 59 (6), 1070-1100. http://dx.doi.org/10.1080/02724980543000123.

Dhar, R., Gorlin, M., 2013. A dual-system framework to understand preference construction processes in choice. J. Consum. Psychol. 23 (4), 528-542. http://dx.doi. org/10.1016/j.jcps.2013.02.002.

Folkes, V.S., 1984. Consumer reactions to product failure: an attributional approach. J. Consum. Res. 10 (4), 398-409. http://dx.doi.org/10.1086/208978.

Hayes, A.F., 2013. Introduction to Mediation, Moderation, and Conditional Process Analysis: a Regression Based Approach. Guilford Press, New York.

Hui, M.K., Toffoli, R., 2002. Perceived control and consumer attribution for the service encounter. J. Appl. Social. Psychol. 32 (9), 1825-1844. http://dx.doi.org/10.1111/j. 
1559-1816.2002.tb00261x.

Kahneman, D., 2011. Thinking Fast and Slow. Farrar, Straus and Giroux, New York. http://dx.doi.org/10.1017/CBO9781107415324.004.

Kahneman, D., Frederick, S., 2002. Representativeness revisted: attribute substitution in intuitive judgement. In: Gilovich, T., Griffin, D., Kahneman, D. (Eds.), Heuristics of Intuitive Judgment: Extensions and Applications. Cambridge University Press, New York. http://dx.doi.org/10.1038/2251090a0.

Mattila, A.S., Wirtz, J., 2001. Congruency of scent and music as a driver of in-store evaluations and behavior. J. Retail. 77 (2), 273-289. http://dx.doi.org/10.1016/ S0022-4359(01)00042-2.

Mezulis, A.H., Abramson, L.Y., Hyde, J.S., Hankin, B.L., 2004. Is there a universal positivity bias in attributions? A meta-analytic review of individual, developmental, and cultural differences in the self-serving attributional bias. Psychol. Bull. 130 (5), 711-747. http://dx.doi.org/10.1037/0033-2909.130.5.711.

Milliman, R.E., 1986. The influence of background music on the behavior of restaurant patrons. J. Consum. Res. 13 (2), 286-289. http://dx.doi.org/10.1086/209068.

Peterson, C., Semmel, A., von Bayer, C., Abramson, L.Y., Metalsky, G.I., Seligman, M.E.P., 1982. The attributional style questionnaire. Cogn. Ther. Res. 6 (3), 287-300. http:// dx.doi.org/10.1007/BF01173577.

Pronin, E., 2013. When the mind races: effects of thought speed on feeling and action. Curr. Dir. Psychol. Sci. 22 (4), 283-288. http://dx.doi.org/10.1177/ 0963721413482324.

Pronin, E., Jacobs, E., Wegner, D.M., 2008. Psychological effects of thought acceleration. Emotion 8 (5), 597-612. http://dx.doi.org/10.1037/a0013268.

Pronin, E., Wegner, D.M., 2006. Manic thinking - independent effects of thought speed and thought content on mood. Psychol. Sci. 17 (9), 807-813. http://dx.doi.org/10.
$1111 / j .1467-9280.2006 .01786 . x$.

Raghunathan, R., Trope, Y., 2002. Walking the tightrope between feeling good and being accurate: mood as a resource in processing persuasive messages. J. Personal. Soc. Psychol. 83 (3), 510-525. http://dx.doi.org/10.1037/0022-3514.83.3.510.

Richins, M.L., 1983. Negative word-of-mouth by dissatisfied consumers: a pilot study. Journal of Marketing 47. pp. 68-78. http://dx.doi.org/10.2307/3203428.

Richins, M.L., 1987. A multivariate analysis of responses to dissatisfaction. J. Acad. Mark. Sci. 15 (3), 24-31. http://dx.doi.org/10.1007/BF02722168.

Saini, R., Thota, S.C., 2010. The psychological underpinnings of relative thinking in price comparisons. J. Consum. Psychol. 20 (2), 185-192. http://dx.doi.org/10.1016/j.jcps. 2010.02.003.

Trope, Y., Ferguson, M., Raghunathan, R., 2001. Mood as a resource in processing selfrelevant information. In: In: Forgas, J.P. (Ed.), Handbook of Affect and Social Cognition Mahwah: Lawrence Erlbaum Associates Publishers, pp. 256-274.

Tversky, A., Kahneman, D., 1974. Judgment under uncertainty: heuristics and biases. Science 185 (4157), 1124-1131. http://dx.doi.org/10.1126/science.185.4157.1124.

Weiner, B., 1985. An attributional theory of achievement motivation and emotion. Psychol. Rev. 92 (4), 548-573. http://dx.doi.org/10.1007/978-1-4612-4948-1 6.

Weiner, B., 2000. Attributional thoughts about consumer behavior. J. Consum. Res. 27 (3), 382-387. http://dx.doi.org/10.1086/317592.

Weiner, B., 2014. The attribution approach to emotion and motivation: history, hypotheses, home runs, headaches/heartaches. Emot. Rev. 6 (4), 353-361. http://dx. doi.org/10.1007/3-540-35375-5.

Yang, K., Friedman-Wheeler, D.G., Pronin, E., 2014. Thought acceleration boosts positive mood among individuals with minimal to moderate depressive symptoms. Cogn. Ther. Res. 38 (3), 261-269. http://dx.doi.org/10.1007/s10608-014-9597-9. 